\title{
APRENDIZAGEM NO CONTEXTO ORGANIZACIONAL PARA A SUSTENTABILIDADE: UM ESTUDO DE CASO
}

\author{
GABRIELA ALMEIDA MARCON NORA, M.SC. | UFSC \\ EDUARDO JUAN SORIANO-SIERRA, Ph.D. |UFSC
}

\section{INTRODUÇÃO}

Existe uma nova pressão sobre as instituições de ensino superior para que abracem sua responsabilidade socioambiental - ainda um desafio que requer aprendizagem. As Universidades públicas brasileiras, em função de todas as suas atribuições em ensino, pesquisa e extensão, possuem aquisições volumosas. Neste contexto surgiu a pergunta deste estudo: Como as preocupações com a sustentabilidade nas compras públicas fomentam a aprendizagem no contexto de uma universidade brasileira? O objetivo geral da presente pesquisa foi "Compreender como as preocupações com a sustentabilidade nas compras públicas fomentam a aprendizagem individual no contexto organizacional de uma universidade brasileira".

Para atingir o objetivo geral proposto, foram estabelecidos quatro objetivos específicos: a) Examinar os critérios para sustentabilidade nas compras públicas; b) Verificar a maneira como o conhecimento é compartilhado entre os sujeitos no ambiente da pesquisa; c) Identificar processos de aprendizagem no ambiente de trabalho eventualmente existentes; d) Descrever os pontos críticos dentro do processo de aprendizagem individual para a sustentabilidade no ambiente.

Para o alcance deste objetivo, de abordagem qualitativa e natureza exploratória, de horizonte transversal, foi escolhido o estudo de caso como estratégia investigativa. A ênfase, em termos de nível de análise da aprendizagem, esteve nos indivíduos. Foram coletados dados primários e secundários. Realizou-se entrevistas semiestruturadas com oito informantes com vivência no que diz respeito ao ambiente e ao tema da pesquisa. Após a coleta de dados, utilizou-se o software MAXQDA Analytics Pro 2018, para auxílio na realização das análises, permitindo criar alguns códigos e categorizar excertos das transcrições.

\section{DISCUSSÃO E RESULTADOS}

Não há uma definição singular para aprendizagem individual no ambiente organizacional ou no ambiente de trabalho. A literatura acadêmica apresenta múltiplos entendimentos sobre o tema (BILLETT, 2002; BENOZZO; COLLEY, 2012).

Foi realizado um estudo de caso único na UFSC, o qual permitiu explicitar características do ambiente e de seus atores. Identificou-se que o compartilhamento de conhecimentos é mais informal do que codificado. Alguns processos de gestão do conhecimento já foram implementados, mas ainda há bastante espaço para avanços nessa seara.

Sustentabilidade requer engajamento (HANSEN; LEHMANN, 2006). Constatou-se que a legislação é um forte indutor de novos comportamentos (ARROWSMITH, 2004) e, por esta razão, um instrumento de apoio à aprendizagem, sobretudo, no setor público. A cultura organizacional voltada à aprendizagem é importantíssima quando se pretende produzir mudanças no contexto. No ambiente da pesquisa, apesar de haver registros das ações, a aprendizagem ocorre, principalmente, nas trocas intersubjetivas, não em programas de capacitação voltados a este fim. Foram identificados e descritos nos resultados sete pontos críticos para aprendizagem no contexto organizacional que a impulsionam e merecem ser considerados por toda instituição que a deseje promover, quais sejam: i) Liderança; ii) Redes; iii) Cultura Organizacional; iv) Regulação, Controle e Monitoramento; v) Tecnologia; vi) Fatores Motivacionais e vii) Engajamento dos Indivíduos.

O fato de existir a preocupação e uma consciência de que é necessário evoluir no que diz respeito às práticas de sustentabilidade atreladas às compras públicas é um fator positivo dentro da instituição.

\section{LIMITAÇÕES E RECOMENDAÇÕES}

Como limitações, menciona-se o fato de que nem todos os entrevistados, apesar do longo contato e diversidade de questionamentos em cada caso, dispuseram de tempo para mais de uma entrevista. Para estudos futuros, recomenda-se se a análise dos processos de aprendizagem em instituições de ensino superior com ênfase em outros níveis de análise. 


\section{REFERÊNCIAS}

ARROWSMITH, Sue. An assessment of the new legislative package on public procurement. Common Mark Law, [s.l.], v. 41, n. 5, p. 1277-1325, 2004.

BENOZZO, Angelo; COLLEY, Helen. Emotion and learning in the workplace: critical perspectives. Journal of Workplace Learning, [s.I.], v. 24, n. 5, p. 304-316, 29 jun. 2012.

BILLETT, S. Critiquing workplace learning discourses: participation and continuity at work, Studies in the Education of Adults, [s.I.], v. 34, n. 1, 56-67, 2002.

HANSEN, Jens Aage; LEHMANN, Martin. Agents of change: universities as development hubs. Journal of Cleaner Production, [s.l.], v. 14, n. 9, p. 820-829, 2006. 